\title{
Foreign Capital Inflow and Regional Immiserization
}

\author{
Bharat R. Hazari \\ Deakin University \\ Pasquale M. Sgro \\ Deakin University
}

\begin{abstract}
In recent years a number of papers have examined the impact of inflow of foreign capital on welfare in a trade theoretic model. Two fundamental ques tions have been raised in this literature. First, what is the welfare impact of foreign capital inflow under a laissez faire regime? Second, what is the impact of tariff induced capital inflow on welfare? In this paper we depart from the $\mathrm{H}$ eckscher-O hlin framework where there is only one representative agent whose welfare is considered. We exploit a trade theoretic framework to analyse the impact on an inflow of foreign capital on regional welfare, in particular, urban and rural incomes.

The analysis is undertaken in a four goods, two region model where each region produces and consumes its own non-traded good. Foreign capital is only
\end{abstract}


used in the urban region and its inflow is treated initially as exogenous and later endogenised via a movement in the terms-of-trade. An exogenous inflow of foreign capital necessarily raises aggregate urban income irrespective of capi tal intensity conditions. The rural region is 'immiserized' by the inflow of for eign capital provided that the rural traded good is more capital intensive than the rural non-traded good. In this framework rural employment always falls and urban employment always rises. In the case where foreign capital inflow is induced by a change in the terms-of-trade, immiserization may occur in both regions depending on the capital intensities in all sectors. This paper highlights the locational implication of the inflow of foreign capital. (JEL Classification:

$F 2,01, R 1$ )

\section{Introduction}

In recent years the impact of the inflow of foreign capital on welfare has been examined by many authors in the context of international trade. Two fundamental questions have been raised in this literature. First, what is the welfare impact of foreign capital inflow under a laissez faire regime. ${ }^{1} \mathrm{Sec}-$ ond, what is the impact of a tariff induced capital inflow on welfare. ${ }^{2}$ It has been shown that in this context capital inflow may be welfare reducing. This paper departs from the Heckscher-O hlin framework where there is usually only one representative agent whose welfare is considered. There are many instances where many agents exist in an economy and whose welfare cannot be necessarily represented by an aggregate utility function. We utilise a trade theoretic framework to analyse the impact of an inflow of foreign capital on regional welfare, in particular, urban and rural incomes. This distinc-

1. A large number of papers have been written on these issues. For example, Beladi

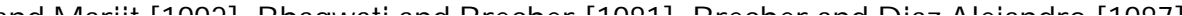


tion between rural and urban incomes is important in policy making in many countries. ${ }^{3}$

The urban and rural regions are distinguished from each other in terms of both production and consumption. Two goods are produced in each region. The urban sector produces an importable good and an urban nontraded good. This non-traded commodity is not consumed by the rural population. The rural region produces the exportable good and a rural non-traded good which is not consumed by the urban population. The representative consumer in the urban and rural regions thus consume a different bundle of goods: the urban agent consumes two traded and the urban non-traded goods while the rural agent consumes the same traded goods and the rural non-traded good. ${ }^{4}$ Urban non-traded goods are mainly consumed by the urban population.

Several interesting results regarding the interrelationship between foreign capital and regional incomes are obtained. First, it is established that foreign capital inflow (both exogenous and endogenous) necessarily 'immiserizes' the rural region provided that the production of the importable good is more capital intensive than the urban non-traded good. The urban region necessarily gains from an inflow of exogenous foreign capital in aggregate terms but not necessarily in per capita terms under the same capital intensity condition. However, the urban region may gain or lose both aggregate and per capita real income as a consequence of endogenous capital inflow induced by a change in the terms-of-trade. We also show that both regions may be 'immiserized' by an endogenous inflow of capital. These results extend the theory of immiserizing growth and foreign capital to regional economics. ${ }^{5}$

\section{A Trade Model for Regional Analysis with Foreign Capital}


returns to factors. The goods $X_{U}$ and $X_{N}$ are produced in the urban region with the help of region specific capital (domestic and foreign) and labour. The commodity, $X_{U}$, is traded both domestically and internationally while good, $X_{N}$, (the non-traded good) is produced and consumed in the urban region only. The employment structure for the urban area is given below:

$$
\begin{aligned}
& a_{K U} X_{U}+a_{K N} X_{N}=\bar{K}_{U}^{d}+K^{F} \\
& a_{L U} X_{U}+a_{L N} X_{N}=E^{U}
\end{aligned}
$$

where $\mathrm{K}_{\longleftarrow}^{d}$ denotes the inelastic supply of region specific domestic capital, $\mathrm{K}^{\mathrm{F}}$ the supply of foreign capital and $\mathrm{E}^{\mathrm{U}}$ the endogenously determined aggregate urban employment. The terms $a_{i j}$ 's are the variable input coefficients and are functions of factor prices as shown below:

$$
a_{i j}=a_{i j}[w, r] \quad[i=K, L, j=U, N]
$$

The terms $w$ and $r$ denote the wage rate and rental on domestic and foreign capital.

The competitive pricing equations for the urban region are:

$$
\begin{aligned}
& a_{L U} w+a_{K U} r=P_{U} \\
& a_{L N} w+a_{K N} r=P_{N}
\end{aligned}
$$

where, $P_{U}$, is the exogenously given relative price of the urban traded good, $P_{N}$, the endogenously determined relative price of the urban non-traded good.

The market for urban non-traded good clears locally in the urban region only. Hence demand equals supply:

$$
D_{N}\left[P_{U}, P_{N}, I^{U}\right]=X_{N}
$$


this price is used as the numeraire for the model.

In the rural region the goods $X_{r}$ and $X_{N r}$ are produced with the region specific rural capital and labour with neoclassical production factors which possess constant returns to scale and diminishing return to factors. The commodity, $X_{r}$, is traded both domestically and internationally. The employment structure for the rural region is given below:

$$
\begin{aligned}
& a_{K_{r}} X_{r}+a_{K N r} X_{N r}=K_{-}^{R} \\
& a_{L r} X_{r}+a_{L N r} X_{N r}=E^{R}
\end{aligned}
$$

where $K_{-}^{R}$ is the inelastically supplied quantity of rural capital and $E^{R}$ the endogenously determined amount of aggregate rural employment. The rural $a_{i j}$ 's are the variable input coefficients and are functions of factor prices as shown below:

$$
a_{i j}=a_{i j}[w, R] \quad[i=k, L, j=r, N r]
$$

where R is the return to rural capital. No foreign capital is used in the rural region. Labour is completely mobile between sectors and regions hence the full employment condition is given below:

$$
E^{U}+E^{R}+L_{-}
$$

where $L$ is the inelastically supplied quantity of total labour .

The competitive pricing structure for the rural region is given below:

$$
\begin{aligned}
& a_{L r} w+a_{K r} R=P_{r}=1 \\
& a_{L N r} w+a_{K N r} R=P_{N r}
\end{aligned}
$$

where $P_{r}$ is the exogenously given price of the good, $X_{r}$, and is chosen as the numeraire and set equal to unity. The relative price of the non-traded good,

D ic andononniclis datarminad 
where $D_{r u}$ and $D_{r r}$ represent rural consumption of the urban and rural traded good respectively.

The market clearing equations for $X_{U}$ and $X_{r}$, the traded goods are given below:

$$
\begin{aligned}
& D_{u U}+D_{r U}=X_{U}+M \\
& D_{r r}+D_{U r}=X_{r}-E
\end{aligned}
$$

where $M$ represents imports and $E$ exports.

When $\mathrm{K}^{\mathrm{F}}$ is treated as an endogenous variable its flow can be a function of several variables. However, for analytical convenience it is assumed to be a function of $\mathrm{P}_{U}$ as shown below: ${ }^{6}$

$$
\mathrm{K}^{\mathrm{F}}=\mathrm{K}^{\mathrm{F}}\left[\mathrm{P}_{\mathrm{U}}\right]
$$

It is assumed that, $X_{U}$, is the most capital intensive good in the economy, hence; $\hat{r}>0$ when $P_{u}$ increases. Assuming that the domestic $r$ rises above the international rental on capital, this change induces an inflow of foreign capital, hence $\hat{K}^{\mathrm{F}}>0$.

This completes the specification of a regional model of trade with foreign capital. To derive some results it is easier to use a reduced form of the above model. From the assumptions of profit maximisation and an interior solution, the following supply functions are obtained. ${ }^{7}$ Throughout the paper it is assumed that the goods are substitutes for each other.

$$
\begin{aligned}
& X_{U}=X_{U}\left[P_{U}, P_{N}, K^{F}, E^{U}\right] \\
& X_{N}=X_{N}\left[P_{U}, P_{N}, K^{F}, E^{U}\right] \\
& X_{r}=X_{r}\left[P_{U}, P_{N r}, E^{R}\right] \\
& X_{N-r}=X_{N-1}\left[P_{\ldots} \ldots P_{M 1 . .} E^{R}\right]
\end{aligned}
$$




\section{Results $\mathcal{E}$}

In this section we first analyse the effect of an exogenous increase in foreign capital on outputs, employment and most importantly regional wfore (income 0 rom equations (4), (5), (12), and (13) we obtain a solution for the inter-relationship between the relative price of the urban non-traded good and the rural non-fraded good, as shown below. This relationship exists because of labour mobility and the consumption of internation 0 aded goods in both regions.

where

$$
\hat{P}_{\mathrm{Nr}}=\frac{||^{\mathbb{R}}}{||^{\bar{v}}} \hat{P}_{\mathrm{N}}
$$

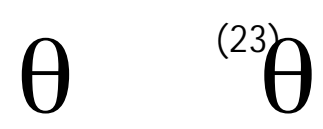

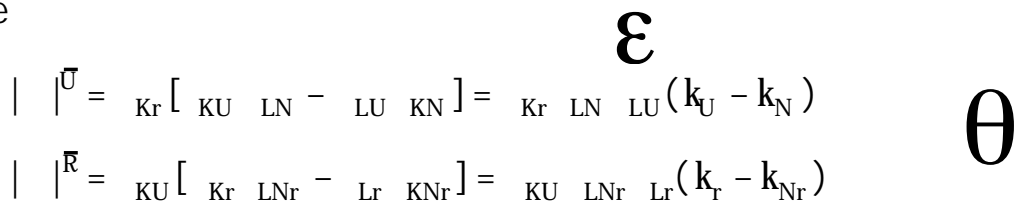

where $\theta_{\mathrm{ij}}{ }^{\prime} \mathrm{s}$ represent factor shares. Note that $\hat{\mathrm{P}_{\mathrm{N}}}$ and $\hat{\mathrm{P}_{\mathrm{Nr}}}$ are monotonically related. We shall assume throughout this paper that in each region the internationally traded goods are more capital intensive than the non-traded goods, i.e., $\theta_{\mathrm{KU}} \theta_{\mathrm{LN}}-\theta_{\mathrm{LU}} \theta_{\mathrm{KN}}>0$ and $\theta_{\mathrm{Kr}} \theta_{\mathrm{LNr}}-\theta_{\mathrm{Lr}} \theta_{\mathrm{KNr}}>0$.

By differentiating equations (6), (7), (11), (14), (15), (20), and (22) with respect to $\mathrm{K}^{\mathrm{F}}$ and using (21) to eliminate $\hat{P}_{\mathrm{Nr}}$ we obtain:

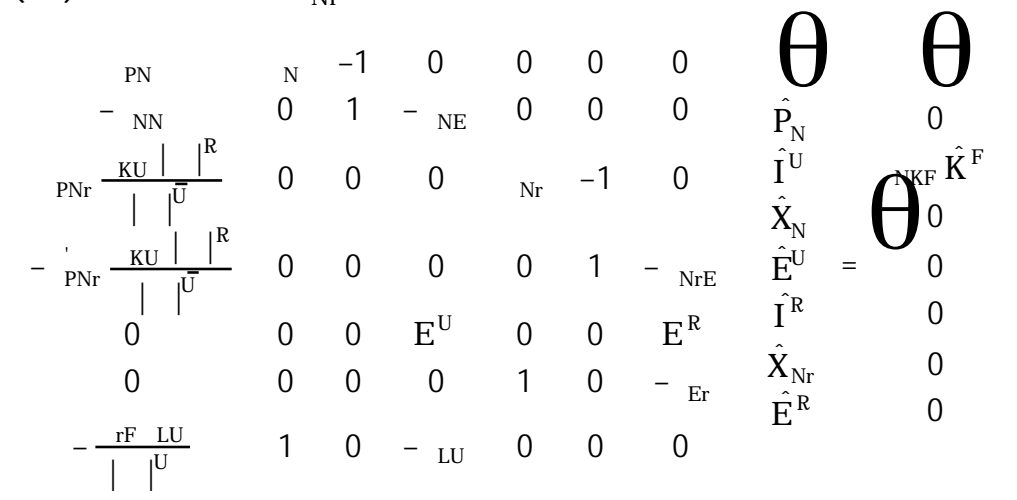




$$
\begin{aligned}
& { }_{\mathrm{PNr}}=\frac{\mathrm{P}_{\mathrm{Nr}}}{D_{\mathrm{Nr}}} \frac{\mathrm{D}_{\mathrm{Nr}}}{P_{\mathrm{Nr}}}<0=0 \text { wn demand elasticity } \mathrm{X}_{\mathrm{Nr}} \\
& { }_{\mathrm{PNr}}=\frac{\mathrm{P}_{\mathrm{Nr}}}{X_{\mathrm{Nr}}} \frac{X_{\mathrm{Nr}}}{P_{\mathrm{Nr}}}>0=0 \text { wn supply elasticity for } \mathrm{X}_{\mathrm{N}} \\
& \varepsilon \quad \eta \quad \\
& \text { NN }=\frac{P_{N}}{X_{N}} \frac{X_{N}}{P_{N}}>0=\text { Own supply elasticity for } X_{N} \\
& N E=\frac{E^{U}}{X_{N}} \frac{X_{N}}{E^{U}} \quad=\text { Rybczynski labour elasticity of } X_{N} \\
& { }_{\mathrm{NrE}}=\frac{E^{R}}{X_{N r}} \frac{X_{N r}}{E^{R}} \quad=\text { Rybczynski labour elasticity of } X_{0} \\
& { }_{N K F}=\frac{K^{F}}{X_{N}} \frac{X_{N}}{K^{F}} \quad=\text { Rybczynski capital elasticity of } X_{N} \\
& \text { Q } \\
& N_{N}=\frac{I^{U}}{D_{N}} \frac{D_{N}}{I^{U}}>0=\text { Income elasticity for good } X_{N} \\
& \mathrm{Nr}=\frac{\mathrm{I}^{\mathrm{R}}}{\mathrm{D}_{\mathrm{Nr}}} \frac{\mathrm{D}_{\mathrm{Nr}}}{\mathrm{I}^{\mathrm{R}}}>0=\text { Income elasticity for good } \mathrm{X}_{\mathrm{Nr}}
\end{aligned}
$$

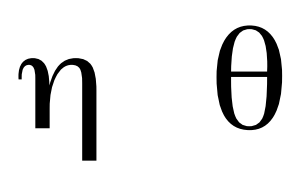

This paper is mainly concerned with exploring changes in regiond iin come and the relative $\mathcal{C}$ price of non-traded goods. The solutions are given below:

$$
\begin{aligned}
& \left.\hat{P}_{N}=\frac{E^{U}{ }_{N K F}(N r E r-N r E}{N}\right) \hat{K}^{F} \\
& \hat{\imath}^{U}=\frac{r F L U E^{U}{ }_{N K F}\left(\mathrm{NrEr}^{-}{ }_{N R E}\right)}{||^{U}|D|} \hat{K}^{F} \\
& +\frac{{ }^{-} E^{R}{ }_{N K E}\left({ }_{P N r} A-{ }_{P N r} A\right)}{I \cap I} \hat{K}^{F}
\end{aligned}
$$




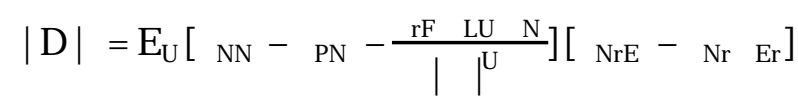

$$
\begin{aligned}
& +E_{R}\left[{ }_{P N r} A-{ }_{P N r} A\right]\left[{ }_{N E}-{ }_{N} L U\right]>0
\end{aligned}
$$

The sign of $|D|>0$. This follows from the fact that $\left[\varepsilon_{\mathrm{NrE}}-\eta_{\mathrm{Nr}} \theta_{\mathrm{Er}}\right]$ and $\left[\varepsilon_{\mathrm{NE}}-\eta_{\mathrm{N}} \theta_{\mathrm{LU}}\right]$ are positive from the magnification effect of J ones [1965]. The term [ $\left.{ }_{N N}-{ }_{P N}-\frac{\mathrm{rF}_{L} L^{N}}{||^{v}}\right]$ is assumed positive to satisfy the stability condition in the market for the urban non-traded good. The following propositions emerge from the analysis.

Proposition 1: An increase in foreign capital inflow necessarily raises the rel ative price of the urban and rural non-traded goods provided that $k_{u}>k_{N}$ and $k_{r}>k_{N r}$. From the Stolper-Samuelson theorem it follows that $w$ rises and the return to capital in both regions falls.

Proposition 2: An increase in foreign capital inflow necessarily increases urban income (welfare) and lower rural income (welfare) provided that $\mathrm{k}_{\mathrm{u}}>\mathrm{k}_{\mathrm{N}}$ and $\mathrm{k}_{\mathrm{r}}>\mathrm{k}_{\mathrm{N} r}$.

It is clear from Proposition 2 that an inflow of foreign capital raises urban income and lowers rural income provided the factor intensity conditions are satisfied. The intuitive explanation of this result is contained in Proposition 1 and is developed in terms of Figure 1 . Since both regions use labour the relative price of the urban and rural non-traded goods are related to each other via the factor intensity conditions. The real income effect of these price changes on factor rewards are different in the two regions due to non-identical consumption baskets. Proposition 1 shows that the rental on rural capital necessarily falls as a consequence of foreign capital inflow. This decline caus-

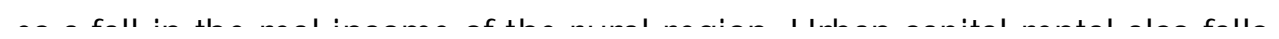




\section{Figure 1}

\section{Foreign Capital Inflow and Regional Welfare}

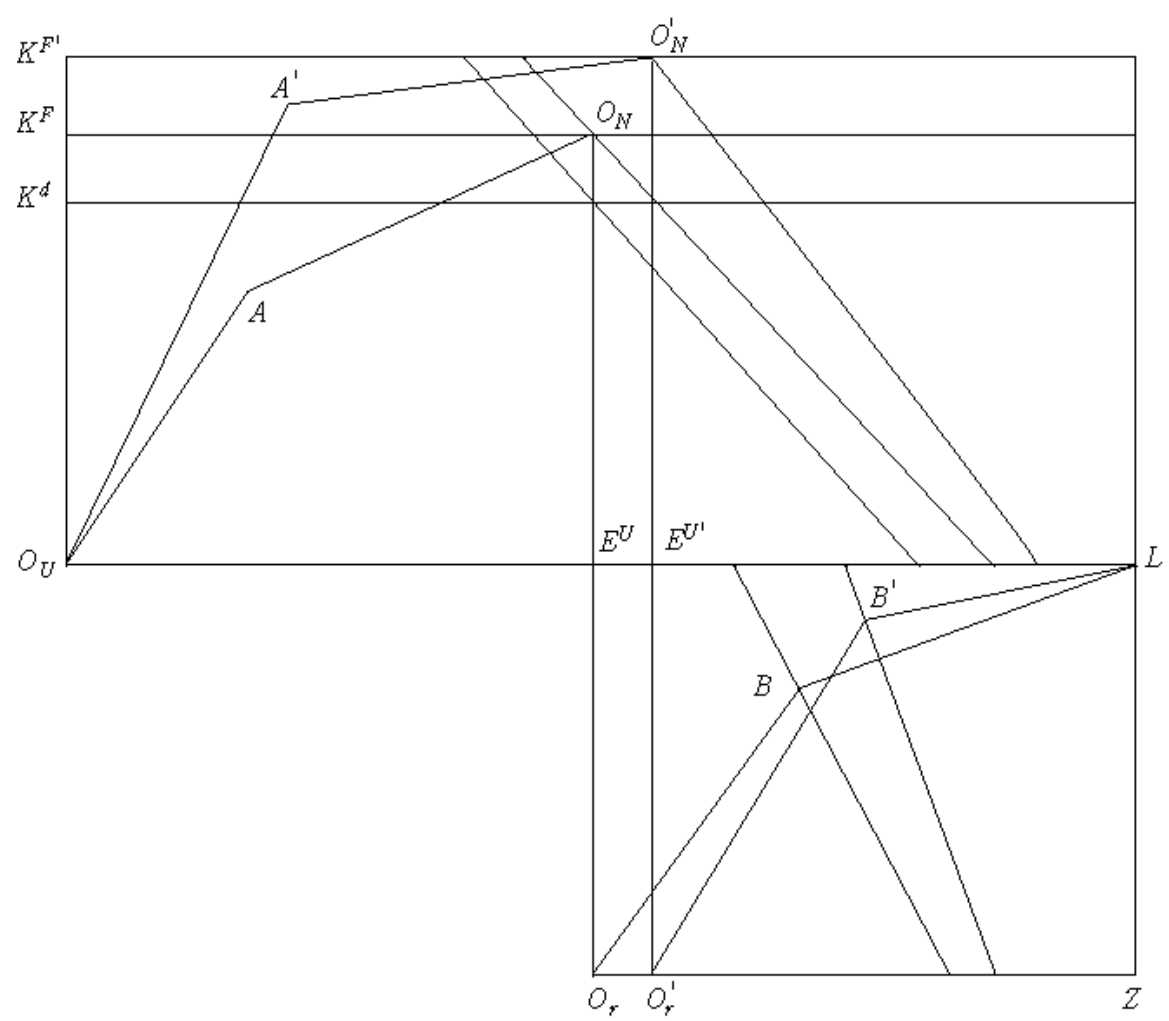

economy as a whole. The vertical axis in the top half represents urban capital which consists of domestic and foreign capital $\mathrm{O}_{U} \mathrm{~K}^{d}$ domestic capital and $K^{d} K^{f}$ foreign capital. Given the exogenous values of $P_{U}, K_{F}, L_{+} P_{r}(=1), K_{U}^{d}$, and $K_{\rightarrow}^{R}$ the endogenous variables can be solved. The employment vectors corresponding to the equilibrium values of $X_{U}$ and $X_{N}$ are given by $O_{U} A$ and $\mathrm{AO}_{\mathrm{N}}$.

In Figure 1 the employment vectors give rise to total urban unemploy- 
Let us suppose that the amount of foreign capital increases from $\mathrm{K}^{\mathrm{d}} \mathrm{K}^{\mathrm{F}}$ to $\mathrm{K}^{\mathrm{d}} \mathrm{K}^{\mathrm{F}}$. Since this increase is at non-constant factor and commodity prices the new equilibrium value of $E^{U}$ is represented by $O_{N}^{\prime}$, the employment vectors by $O_{U} A^{\prime}$ and $A^{\prime} O_{N}^{\prime}$. In this case outputs of sector $X_{U}$ increases and $X_{N}$ falls. Urban employment increases from $\mathrm{O}_{U} E^{U}$ to $\mathrm{O}_{U} \mathrm{E}^{U}$ '. As the urban region attracts both foreign capital and labour its income increases with the inflow of foreign capital. Note that the wage rental ratio in the urban region represented by the slope of the line through $O_{N}$ is flatter than the through $O_{N}^{\prime}$ reflecting the result that it has increased. The wage rental ratio in the rural sector also rises as reflected by the change in the slope of the line through $B$ and $B^{\prime}$. It is obvious from examining equations (26) and (27) that the urban region gains more than the rural region. Hence, the rural region may be compensated by a suitable policy. This result is in keeping with the Pareto Rule.

We now proceed to examine the effect of a change in the terms of trade on regional incomes assuming the endogeneity of foreign capital. By differentiating the regional income equations (7) and (15) we obtain:

$$
\begin{aligned}
& P_{U d} D_{U U}+d D_{U r}+P_{N} d D_{N}+D_{U U} d P_{U}+D_{N} d P_{N} \\
& =P_{U} d X_{U}+P_{N} d X_{N}-r d K^{F}-K^{F} d r+X_{U} d P_{U}+X_{N} d P_{N}
\end{aligned}
$$

which reduces to:

$$
d l^{U}=-\left(D_{U U}-X_{U}\right) d P_{U}+w d E^{U}-K^{F} d r
$$

where $\mathrm{dl}^{U}=\mathrm{P}_{U} \mathrm{dD}_{\mathrm{UU}}+\mathrm{dD}_{\mathrm{Ur}}+\mathrm{P}_{\mathrm{N}} \mathrm{dD}_{\mathrm{N}}$. In a similar manner we derive the change in real income for the rural region:

$$
\mathrm{dl}^{\mathrm{R}}=-\mathrm{D}_{\mathrm{rU}} \mathrm{dP} \mathrm{P}_{\mathrm{U}}+\mathrm{WdE}^{\mathrm{R}}
$$




$$
E^{U}=E^{U}\left[K^{F}\left(P_{U}\right)\right]
$$

It is assumed that:

$$
\frac{\mathrm{dE}^{\mathrm{U}}}{\mathrm{dP}_{\mathrm{U}}}=\frac{\mathrm{E}^{\mathrm{U}}}{\mathrm{K}^{\mathrm{F}}} \frac{\mathrm{K}^{\mathrm{F}}}{\mathrm{P}_{\mathrm{U}}}>0
$$

This states that labour follows capital.

The expression for the change in the rental on capital is obtained by assuming that $\mathrm{P}_{\mathrm{N}}$ is initially constant, ${ }^{8}$ hence by differentiating equating (4) and (5) we obtain:

$$
d r=\frac{L N}{\mid l^{U}} d P_{U}
$$

From equation (29) and (30) it follows:

Proposition 3: An induced inflow of foreign capital necessarily 'immiserizes' the rural region.

Proposition 4: An induced inflow of foreign capital raises (lowers) welfare in the urban region provided $-\left(D_{U U}-X_{U}\right) d_{U}+W d E^{U}-K^{F} d r>0(<0)$.

The rural region suffers a welfare loss due to two reasons. First, it's welfare declines due to a terms of trade effect which is captured by the terms $D_{r u} d P_{u}$. The second source of welfare decline in this region arises because labour follows foreign capital and migrates to the urban region as captured by the terms $\mathrm{wdE}^{\mathrm{R}}$.

The income expression for the urban region is more complicated. From equation (29) it is obvious that there are three effects: the terms of trade effect $\left(-\left(D_{U U}-X_{U}\right) d P_{U}\right)$, the influence of migratin wdE ${ }^{U}$ and impact of repatriation payments. In a regional model it is not essential for $\left(D_{u U}-X_{U}\right)$ to be 
region. The repatriation payments depend on the nature of the model under consideration. For example in the tariff induced flow case of $d r=0$. On the other hand if there are some elements of bilateral or multilateral monopoly power in trade then $\mathrm{dr} \geq 0$ and this possibility is captured in Proposition 4.

\section{Conclusion}

This paper clearly shows the difference between the impact of exogenous vis-à-vis endogenous inflow of foreign capital on regional income (welfare). Given the structure of our model the region that does not receive foreign capital is always immiserized for the intensities we have assumed. In the urban region the results are not as clear cut. An exogenous inflow of foreign capital increases urban welfare, however, an endogenous inflow may increase or lower urban welfare. These results provide insights for targeting the inflow of foreign capital.

\section{References}

B eladi, H. and S. M arjit [1992], "F oreign Capital and Protectionism," Cana dian Journal of E conomics 25; pp. 233-238.

Bhagwati, J. and R. A. Brecher. [1981], "Foreign Ownership and the Theory of Trade and Welfare," Journal of Political Economics 89; pp. 497-454.

B recher, R. A. and R. Findlay [1983], "Tariffs, Foreign Capital and $\mathrm{N}$ ational Advantage," Journal of International Economics 14; pp. 277-88.

Brecher, R. A. and C. Diaz-Alejandro [1987], "Tariffs, Foreign Capital and Immiserizing Growth," J ournal of International Economics 7; pp. 317322.

Hazari, B. R. and P. M. Sgro. [1991], "Urban-Rural Structure Adjustment, 
M obility and Welfare," Journal of International Trade and Economic

Development 1; pp. 139-159.

J ones, R. W. [1965], "The Structure of Simple General Equilibrium M odels," Journal of Political Economy 73; pp. 557-572.

Jones, R. W. [1984], "Protection and the Harmful Effects of Endogenous Capital Flows," E conomics Letters 15; pp. 325-30.

Komiya, R. [1967], "N on-Traded Goods and the Pure Theory of International Trade," International Economic Review 8; pp. 132-152.

M undell, R. [1960], "The Pure Theory of International Trade," American Economic Review 50; pp. 321-35. 